\title{
Novel domain arrangement in the crystal structure of a truncated acetyl-CoA synthase from Moorella thermoaceticat, $\neq$
}

\author{
Anne Volbeda ${ }^{*}$, Claudine Darnault $§$, Xiangshi Tan $\|, \#$, Paul A. Lindahıl ${ }^{*}$, and Juan C. \\ Fontecilla-Camps $\S,{ }^{*}$ \\ §Laboratoire de Cristallographie et Cristallogenèse des Protéines, Institut de Biologie Structurale \\ Jean-Pierre Ebel, CEA, CNRS, Université Joseph Fourier, 41 Rue Jules Horowitz, F-38027 \\ Grenoble, France \\ "Departments of Chemistry and of Biochemistry and Biophysics,Texas A\&M University, College \\ Station, Texas 77843.
}

\begin{abstract}
Ni-dependent Acetyl-CoA synthase (ACS) and CO dehydrogenase (CODH) constitute the central enzyme complex of the Wood-Ljungdahl pathway of acetyl-CoA formation. The crystal structure of a recombinant bacterial ACS lacking the $\mathrm{N}$-terminal domain that interacts with $\mathrm{CODH}$ shows a large reorganization of the remaining two globular domains, producing a narrow cleft of suitable size, shape and nature to bind CoA. Sequence comparisons with homologous archaeal enzymes that naturally lack the $\mathrm{N}$-terminal domain show that many amino acids lining this cleft are conserved. Besides the typical [4Fe-4S] center, the A-cluster contains only one proximal metal ion that, according to anomalous scattering data, is most likely $\mathrm{Cu}$ or $\mathrm{Zn}$. Incorporation of a functional $\mathrm{Ni}_{2} \mathrm{Fe}_{4} \mathrm{~S}_{4} \mathrm{~A}$-cluster would require only minor structural rearrangements. Using available structures, a plausible model of the interaction between CODH and the smaller ACS in archaeal multi-enzyme complexes is presented, along with a discussion of evolutionary relationships of the archaeal and bacterial enzymes.
\end{abstract}

\begin{abstract}
Ni-dependent acetyl coenzyme A synthase (ACS) is a NiFeS-cluster enzyme that requires strict anoxic conditions to function. In the acetogenic bacterium Moorella thermoacetica (Mot), the ACS $\alpha$-subunit forms an $\alpha_{2} \beta_{2}$ heterotetramer with the Ni-containing carbon monoxide dehydrogenase $(\mathrm{CODH}) \beta$-subunit (1). This association constitutes the central enzyme complex of the anaerobic Wood-Ljungdahl pathway of acetyl-CoA synthesis from $\mathrm{CO}_{2}(2,3)$. The structure of this complex is known in two crystal forms $(4,5)$ and shows a long hydrophobic tunnel network that allows the $\mathrm{CO}$ produced at the $\mathrm{CODH}$ active site, the $\mathrm{C}$-cluster, to be used at the ACS active site, the A-cluster, without being released to the medium. Our understanding of $\mathrm{CO}_{2}$ reduction to $\mathrm{CO}$ by $\mathrm{CODH}$ has progressed significantly thanks to the recent crystal structures of key catalytic intermediates in the homodimeric $\beta_{2}$ enzyme from
\end{abstract}

\footnotetext{
$\dagger$ This study was supported by institutional funding from the CEA and the CNRS and by the National Institute of Health (GM046441 PAL).

\$The atomic coordinates and structure factors (accession number 3GIT) have been deposited in the Protein Data Bank, Research Collaboratory for Structural Bioinformatics (http://www.pdb.org).

*To whom correspondence should be addressed. AV: Tel. +33438789606, Fax +33438785122, E-mail anne.volbeda@ibs.fr; JCFC: Tel. +33438785920, Fax +33438785122 , E-mail juan.fontecilla@ibs.fr..

\#Current address: Department of Chemistry, Institute of Biomedical Sciences, Fudan University, Shanghai, 200043, P.R. China

Supporting Information Available. Superposition statistics of bacterial CODH/ACS and archaeal CODH, sequence alignment of bacterial ACS with archaeal CODH and structure comparison of CODH and HCP. This material is available free of charge via the Internet at http://pubs.acs.org.
} 
Carboxydothermus hydrogenoformans (Ch) (6) and the heterotetrameric $\alpha_{2} \varepsilon_{2}$ enzyme from the archaeon Methanosarcina barkeri (Meb) (7), see also (8). However, many mechanistic details of acetyl-CoA formation by ACS have not yet been elucidated. The active A-cluster has been characterized as a $\mathrm{Ni}_{2} \mathrm{Fe}_{4} \mathrm{~S}_{4}$ center in the crystal structures of both bi-functional $\mathrm{CODH} / \mathrm{ACS}_{M o t}$ and mono-functional $\mathrm{ACS}_{C h}(5,9)$, in agreement with many previous studies, as reviewed in $(10,11)$. Catalysis involves three substrates, $\mathrm{CoA}, \mathrm{CO}$ and the cobalt-containing methyl-carrying corrinoid iron-sulfur protein $(\mathrm{CoFeSP})$ :

$$
\mathrm{CoA}-\mathrm{S}^{-}+\mathrm{CO}+\mathrm{CH}_{3}{ }^{-}-\mathrm{Co}(\mathrm{III}) \mathrm{FeSP} \rightleftarrows \mathrm{CoA}-\mathrm{SC}(\mathrm{O}) \mathrm{CH}_{3}+\mathrm{Co}(\mathrm{I}) \mathrm{FeSP} .
$$

At least 5 steps take place at the A-cluster during catalysis: (i) binding of $\mathrm{CO}$, (ii) transfer of the methyl group from CoFeSP, (iii) formation of an acetyl intermediate, (iv) binding of $\mathrm{CoA}$ and (v) formation of acetyl-CoA. In addition, ACS requires reductive activation (12). This is so because the methyl group is provided by $\mathrm{CoFeSP}$ as a $\mathrm{CH}_{3}{ }^{+}$cation (13) and two electrons are required to form a carbon-metal bond, most likely with the proximal $\mathrm{Ni}$ ion of the A-cluster. The two electrons are recovered upon reductive elimination of the acetyl intermediate to form acetyl-CoA. So far, crystal structures of well-defined catalytic intermediates of ACS have not been reported.

Here we report the crystallographic analysis of a truncated form of $\mathrm{ACS}_{M o t}$, with a molecular mass of $49 \mathrm{kDa}$ called $\alpha_{49}$ (14). Because it lacks the 310 residue-long $\mathrm{N}$-terminal domain $\alpha_{49}$ resembles the homologous ACS $\beta$ subunit of the acetyl-CoA decarbonylase/synthase (ACDS) multi-enzyme complex found in methanogenic archaea. To avoid confusion, we will use the nomenclature $A 1, A 2$ and $A 3$ for ACS domains, and $C 1, C 2$, etc., for CODH domains, regardless their origin. In $\mathrm{ACS}_{M o t}, A l$ is involved in extensive inter-subunit interactions with $\mathrm{CODH}$ and contains a significant part of the hydrophobic tunnel that connects the $\mathrm{C}$ - and $\mathrm{A}$ clusters $(4,5)$. The isolated, recombinant archaeal ACS can be activated by adding $\mathrm{NiCl}_{2}$. According to metal analyses and spectroscopic studies, the reconstituted Methanosarcina thermophila (Met) ACS contains, like its bacterial counterparts, a classical $\mathrm{Ni}_{2} \mathrm{Fe}_{4} \mathrm{~S}_{4}$ A-cluster (15-17). The ACDS complex also contains $\gamma \delta \mathrm{CoFeSP}$ heterodimers and $\alpha_{2} \varepsilon_{2}$ hetero-tetramers, with $\alpha_{2}$ corresponding to CODH (18). It has been shown that the hydrophobic tunnels of both the bacterial and the archaeal enzymes can bind xenon $(5,7,19)$. The absence of the bacterial tunnel-containing $A l$ domain in archaeal ACS raises the question how $\mathrm{CO}$ diffuses between the A- and C-clusters in the archaeal ACDS complex.

The crystal structure of $\mathrm{ACS}_{M o t}$ has been determined in closed $\left(\alpha_{\mathrm{C}}\right)$ and open $\left(\alpha_{\mathrm{O}}\right)$ conformations (5). The difference between the two structures is due to a large movement of $A 1$, which in $\alpha_{\mathrm{O}}$ blocks the connection between the A-cluster, bound to domain $A 3$, and the tunnel network $(5,20)$. Conversely, when the enzyme is in the $\alpha_{C}$ conformation, the A-cluster can bind the $\mathrm{CO}$ produced at the $\mathrm{C}$-cluster, because the connection to the hydrophobic tunnel network is open. Only inactive $\mathrm{NiCuFe}_{4} \mathrm{~S}_{4}$ and $\mathrm{NiZnFe}_{4} \mathrm{~S}_{4}$ A-clusters have been found in crystal structures of this form $(4,5)$. Functional $\mathrm{Ni}_{2} \mathrm{Fe}_{4} \mathrm{~S}_{4} \mathrm{~A}$-clusters $(10,11)$ have been observed in two $\alpha_{O}$ crystal structures, where the A-cluster is exposed to the medium $(5,9)$. Therefore, the enzyme is likely to accept the methyl group from CoFeSP when it is in the $\alpha_{O}$ conformation. When the enzyme is treated with exogenous $\mathrm{CO}$ a $\mathrm{Ni}(\mathrm{I})-\mathrm{CO}$ complex is formed. Furthermore, ${ }^{57} \mathrm{Fe},{ }^{59} \mathrm{Ni}$ and ${ }^{13} \mathrm{C}$ isotopic labeling experiments have shown that $\mathrm{Ni}, \mathrm{CO}$ and the $[4 \mathrm{Fe}-4 \mathrm{~S}]$ cluster interact magnetically giving rise to an EPR spectrum known as the $\mathrm{NiFeC}$ signal (10,11 and references therein).

Purified recombinant $\alpha_{49}$ contains $\sim 4 \mathrm{Fe}$ and $0.5 \mathrm{Ni}$ per A-cluster (14). Incubation with $\mathrm{NiCl}_{2}$ followed by reduction with dithionite and exposure to $\mathrm{CO}$ yielded an EPR signal reminiscent of $\mathrm{NiFeC}$ in terms of g-values and relaxation/saturation properties. The ability to 
generate this pseudo-NiFeC signal indicates that an A-cluster derivative can be reconstituted in the truncated subunit. The spin concentration of this signal was only $\sim 25 \%$ of that normally observed for $\mathrm{NiFeC}$, and the truncated subunit had no catalytic activity. In this respect, $\alpha_{49}$ resembles other constructs of the Mot enzyme, where metal heterogeneity at the active site and sub-stoichiometric amounts of nickel are a recurrent problem. The $\alpha_{49}$ structure presented here contains a novel metal-containing inactive form of the A-cluster, and a new arrangement of domains $A 2$ and $A 3$. We will call this form $\alpha_{49(\mathrm{~T})}$. Below, we will discuss the relevance of these findings with respect to previous studies on the activity of bacterial and archaeal ACS's. We will also address the possible evolutionary implications of the striking similarities between ACS and CODH domains.

\section{MATERIALS AND METHODS}

\section{Crystallization}

$\alpha_{49}$, a $49 \mathrm{kDa}$ fragment of $\mathrm{ACS}_{M o t}$, was purified after heterologous expression in Escherichia coli, as previously described (14). It contains residues 311-729 of the intact enzyme and a Cterminal His-tag. All crystallization experiments were performed at room temperature in an anaerobic glove box, using the vapor diffusion method. Crystals with maximal dimensions of $0.3 \times 0.3 \times 0.2 \mathrm{~mm}^{3}$ were obtained after six to eight weeks. The best ones grew in hanging drops that were prepared by mixing $1 \mu \mathrm{l}$ of a solution with a protein concentration of $20 \mathrm{mg}$ / $\mathrm{ml}$ and $2 \mathrm{mM}$ sodium dithionite in $50 \mathrm{mM}$ Tris/ $\mathrm{HCl}$ at $\mathrm{pH} 8.0$, with $1 \mu \mathrm{l}$ of a reservoir solution containing $1.4 \mathrm{M}$ ammonium sulfate (AS), $2 \mathrm{mM}$ sodium dithionite and $100 \mathrm{mM}$ Tris/ $\mathrm{HCl}$ at $\mathrm{pH}$ 7.1. After transfer to a stabilization solution containing $2.2 \mathrm{M} \mathrm{AS}$ and $30 \%$ glycerol, in addition to the other reservoir components, crystals were flash-cooled inside the glove box in liquid propane and subsequently stored in liquid nitrogen, as described (21).

\section{X-ray data collection and processing}

Diffraction data were collected to 3.0 A resolution on a MAR CCD165 detector (MAR Research, Germany) by exposing the best crystal to monochromatic $(\lambda=1.008 \AA)$ X-rays under a cold $(\approx 100 \mathrm{~K})$ nitrogen stream. A total of 450 images were collected with $0.4^{\circ}$ oscillations, using the BM30A beamline of the European Synchrotron Radiation Facility in Grenoble, France. Diffraction spots were integrated, scaled, subjected to a zero-dose correction (22) and reduced to structure factor amplitudes with $X D S$ (23). The first 333 images were selected to produce $99.5 \%$ complete data with good intensity statistics (Table 1 ). The crystal belonged to the trigonal space group $\mathrm{P} 3{ }_{1} 21$ with cell dimensions $\mathrm{a}=\mathrm{b}=166.4 \AA$ and $\mathrm{c}=245.2 \AA$. A similar but less well-diffracting crystal with a halved crystallographic c-axis was used to collect data to $3.7 \AA$ resolution at the high energy side of the Ni absorption edge $(\lambda=1.4827 \AA)$. These data were used to check the presence of $\mathrm{Ni}$ (statistics not shown).

\section{Structure solution}

The phase problem was solved by molecular replacement with PHASER (24-26), using the 3 $\AA$ resolution data and domains $A 2$ and $A 3$ of $\mathrm{ACS}_{M o t} \alpha_{\mathrm{O}}$ as search models. For success, it was necessary to exclude the N-terminal region of domain 2 (residues 311-319) and a long interdomain helix (residues 471-499). In addition, low peaks from the rotation function output had to be included in order to find well-contrasting solutions in the translation search. Checks with anomalous difference maps showed that good solutions gave strong peaks for the A-cluster. The asymmetric unit contains six molecules related by non-crystallographic symmetry (ncs) operations close to those of a regular 32 hexamer and a solvent content of about $63 \%$. In the crystal with the smaller unit cell, which contains a trimer per asymmetric unit, the two-fold axes of the hexamer correspond to crystallographic symmetry operations. 


\section{Refinement}

Because of the limited data resolution, refinement was carried out with tight ncs restraints, using REFMAC $(27,28)$ and including TLS refinement (29) to model overall anisotropic displacements of the twelve domains present in the hexamer. Manual model corrections were performed with the TURBO computer graphics package (30). The quality of electron density maps was significantly improved by averaging, using the program SUPERMAP (31). A first six-fold averaged electron density map obtained with molecular replacement phases clearly showed the long helix between domains $A 2$ and $A 3$ that was left out of the starting model. Part of the main chain of the $\mathrm{C}$-terminal His-tag also appeared in this map, at the dimer interfaces of the hexamer (Fig. 1), but the corresponding side chains were only partially resolved during refinement. The first six N-terminal residues of $\alpha_{49(\mathrm{~T})}$ are disordered and therefore were not included in the model. Refinement statistics of the final model are given in Table 1.

\section{Structure and sequence analyses}

Figures 1-3, 5, 7-8 and S2 were prepared with the programs MOLSCRIPT (32) and RASTER3D (33), in addition to CONSCRIPT (34) that was used for the display of electron density maps (Fig. 3). The electrostatic potential surfaces of Figure 4 were determined at $\mathrm{pH}$ 7 with the APBS (35) plugin of PyMOL (http://www.pymol.org), after addition of hydrogen atoms with PDB2PQR (36) using the AMBER force field (37) and $\mathrm{pK}_{\mathrm{a}}$ 's calculated with PROPKA (38), excluding the metal and inorganic sulfur atoms of the A-cluster from the protein. Structural superpositions were performed with the BIOMOL program SUPPOS (http://www.xray.chem.rug.nl/Links/Biomol1.htm). Tunnels and cavity maps in Figures 5, 7, 8 and S2 were calculated with the program CAVsel (A. Volbeda, unpublished). Amino acid sequences used in the manual structure-based alignments in Figures 6 and S1 were obtained from SWISSPROT (http://www.ebi.ac.uk/swissprot/).

\section{RESULTS}

\section{Crystal structure determination}

The structure of $\alpha_{49}$ in the novel $\alpha_{49 \text { (T) }}$ conformation has been solved at $3.0 \AA$ A resolution by molecular replacement (Table 1). There is a regular trimer of dimers in the asymmetric unit (Fig. 1). A similar crystal form with an approximately halved c-axis contained a trimer in the asymmetric unit and diffracted to $3.7 \AA$ resolution. After refinement of the $3.0 \AA$ resolution structure, an average temperature factor of $57.3 \AA^{2}$ was obtained, suggesting small differences in subunit orientations between hexamers. The final model shows good refinement statistics (Table 1), as indicated by a satisfactory geometry and an $\mathrm{R}_{\text {free }}$ of $20.8 \%$ for all structure factor observations between $20 \AA$ and $3.0 \AA$ A resolution. Although we were unable to obtain X-ray

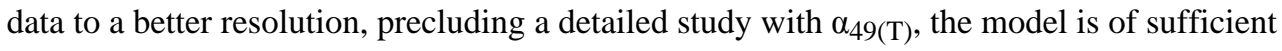
quality to allow the analysis of both fold and major active site differences with previously obtained structures.

\section{Changes with respect to previous ACS structures}

In $\alpha_{49(T)}$, domains $A 2$ and $A 3$ have significantly moved to each other relative to their previously known conformations (Fig. 2). This movement corresponds to a rotation around a hinge region located close to the C-terminus of the long interdomain helix (residues 471-499, shown in orange in Fig. 1). The internal structure of the two domains in the new conformation does not change much: separate $\mathrm{C}_{\alpha}$-superpositions of domains $A 2$ (residues 318 to 491 ) and $A 3$ (residues 494 to 729 ) of $\alpha_{49 \text { (T) }}$ to those of $\alpha_{\mathrm{O}}$ give root-mean-square deviations (rmsd's) of about $0.5 \AA$. Taking $A 2$ as a reference (Fig. 2), the structural change of $\alpha_{49}$ (T) with respect to $\alpha_{O}$ may be described as a rotation ( $\kappa$ ) of domain $A 3$ by $50^{\circ}$ and a translation parallel to the rotation axis $\left(\mathrm{T}_{\text {/I) }}\right.$ of $4.6 \AA$, with a maximal shift of $34 \AA$ in $\mathrm{C}_{\alpha}$ positions. Although the domain conformation 
of $\alpha_{49(\mathrm{~T})}$ is somewhat closer to that of $\alpha_{\mathrm{O}}$ in $\mathrm{ACS}_{\mathrm{Ch}}$ (9), after superposition of their respective $A 2$ domains there is still a substantial difference in the position of domain $A 3\left(\kappa=35^{\circ}, \mathrm{T}_{/ /}=\right.$ $1.3 \AA$ ). Our results indicate that there is much more flexibility in the relative positions of domains $A 2$ and $A 3$ than previously recognized (Fig. 2). In fact, the rearrangement of domain $A 3$ in $\alpha_{49(T)}$ is as extensive as the one observed for domain $A l$ between $\alpha_{C}$ and $\alpha_{O}$ in $\mathrm{ACS}_{\mathrm{Mot}}(5)$. When the corresponding $A 2$ domains are superimposed, there are no bad clashes between $\alpha_{\mathrm{O}} A 1$ and $\alpha_{49(\mathrm{~T})} A 3$. However, the superposition of $\alpha_{\mathrm{C}}$ to $\alpha_{49(\mathrm{~T})}$ leads to the collision of these two domains (not shown). It follows that the $\alpha_{49}$ (T) conformation is compatible with the orientation of $A l$ in $\alpha_{O}$, but not in $\alpha_{C}$.

At the X-ray wavelength of $1.008 \AA$ Ased for data collection with the best $\alpha_{49(T)}$ crystal, a map calculated with $\Delta_{\text {anom }}$ coefficients displayed high peaks at the active site both for the [4Fe-4S] cluster and one metal ion (Fig. 3). This ion occupies the proximal site relative to the cluster, previously called $\mathrm{M}_{\mathrm{p}}(5)$. An equivalent map was calculated with $3.7 \AA$ A resolution data collected at $\lambda=1.4827 \AA$ from the related crystal with the smaller unit cell. In this map, the peak corresponding to the $[4 \mathrm{Fe}-4 \mathrm{~S}]$ cluster was still present but there was no peak at $\mathrm{M}_{\mathrm{p}}$ (not shown). Thus, there is no evidence for the presence of $\mathrm{Ni}$ in the A-cluster in $\alpha_{49(\mathrm{~T})}$. Because (i) the $\lambda$ used is lower than the wavelength corresponding to the $\mathrm{Ni}$ absorption edge and (ii) there is a high electron density peak at $\mathrm{M}_{\mathrm{p}}$ in the map calculated with $2 \mathrm{~F}_{\mathrm{o}}-\mathrm{F}_{\mathrm{c}}$ coefficients, it appears that a metal ion heavier than nickel occupies the proximal site. The most likely candidates are $\mathrm{Cu}$ and $\mathrm{Zn}$, as these metals were also observed in previous crystal structures of $\mathrm{ACS}_{M o t}(4,5)$. A flat $\mathrm{F}_{\mathrm{o}}-\mathrm{F}_{\mathrm{c}}$ difference map for the ion at $\mathrm{M}_{\mathrm{p}}$ was obtained with $75 \%$ occupied $\mathrm{Zn}^{2+}$. The metal ion is tetrahedrally coordinated by an external ligand, modeled as $\mathrm{HS}^{-}$with the same occupancy, and by the thiolate groups of Cys509, Cys595 and Cys597 (Fig. 3).

The cleft formed between $\alpha_{49(\mathrm{~T})}$ domains $A 2$ and $A 3$, is located opposite to where $A 1$ would be in the enzyme. An analysis of electrostatic potential surfaces (Fig. 4) strongly suggests that this cleft may bind the highly negatively charged (39) CoA substrate and acetyl-CoA product: it contains the most extensive complementary positive charge distribution of the truncated structure, which is located mainly on the surface of $A 2$. The same positive patch is visible in the structures of $\alpha_{\mathrm{O}}$ (Fig. 4A) and $\alpha_{\mathrm{C}}$ (Fig. 4B), but in these conformations it is approximately twice as far away from the A-cluster than in $\alpha_{49(\mathrm{~T})}$. Only in the latter conformation (Fig. 4C) does the distance of about $15 \AA$ between the patch and the A-cluster seem compatible with functional binding of the coenzyme.

Results from fluorescence quenching, chemical modification and protection experiments led Wood and co-workers to propose that CoA binding to ACS protects about five tryptophan residues and two arginines from chemical modification $(40,41)$ : i) the modification of these residues causes the loss of the ${ }^{13} \mathrm{CO} /{ }^{12} \mathrm{CO}$ exchange reaction in acetyl-CoA catalyzed by the A-cluster; ii) modification of the arginines modifies the fluorescence of the tryptophan(s) indicating that some are close to each other; iii) at least one of the modified tryptophans must be close to the A-cluster because it perturbs the NiFeC EPR signal; iv) both adenine and 3'dephospho-CoA quench the tryptophan residue(s) fluorescence, suggesting that the 3'phosphate group is not essential for CoA binding; v) the pyrophosphate bridge of CoA binds to arginine(s) as indicated by the protection that added pyrophosphate exerted against the chemical modification of these residues and vi) these modifications only affect the microenvironment around the targeted residues, as shown by $\mathrm{CD}$. The cleft formed between $A 2$ and $A 3$ contains two tryptophans, 418 and 427, and four arginines, 334, 346, 429 and 616 (Fig. 5A). Trp418 is likely to be one of the modified residues because in $\alpha_{49 \text { ( } T}$ it is the closest tryptophan to the A-cluster at $12.5 \AA$ and, consequently, it could influence the NiFeC signal. Trp427 may be also a potential candidate for chemical modification being at $17.5 \AA$ from the A-cluster. Consistent with the results described above (v), arginines 334, 346, 429 and 616 are close to the two tryptophans. 
Coenzyme A could be stabilized through interactions of i) the adenine ring with Trp418 or Trp427 and ii) its pyrophosphate region with the guanidinum group of two of the arginines mentioned above (Fig. 5A). These interactions are also compatible with the approach of the cysteamine moiety of the coenzyme to the $\mathrm{M}_{\mathrm{p}}$ site of the A-cluster through a narrow tunnel that does not exist in the other $\alpha$-subunit conformations (Fig. 5B). Assisted by His 419 , His 408 may abstract a proton from CoA-SH before its putative binding to the apical binding site of $\mathrm{Ni}_{\mathrm{p}}$ (labeled with *). Next it may react with an acetyl group bound equatorially to $\mathrm{Ni}_{\mathrm{p}}$ (at the site labeled with \$). A cavity above the $\mathrm{S}$ atom of the coenzyme shows that there is also enough space for the acetyl-CoA product. We conclude that, if $\alpha_{49(\mathrm{~T})}$ has functional relevance, it may approximate the CoA binding conformation of ACS. The fact, as mentioned above, that the $\alpha_{49 \text { (T) }}$ conformation is incompatible with $\alpha_{C}$ is not surprising because the acetylated ACS, that binds CoA, should not be able to adopt this conformation due to steric hindrance at the Acluster.

\section{Comparison to archaeal enzymes}

In order to investigate whether the domain arrangement in $\alpha_{49(\mathrm{~T})}$ could arise from crystal packing interactions, we compared the amino acid sequences of the two bacterial enzymes of known structure with two methanogenic (Met and Meb) counterparts. Out of the 403 aligned residues, 147, or 36.4\%, are invariant (Fig. 6) suggesting that the bacterial and archaeal ACS's have very similar structures. Out of the 30 residues involved in interactions $(\mathrm{d}<3.8 \AA$ ) between domains $A 2$ and $A 3$ in $\alpha_{49(T)}, 18$, or $60 \%$, are invariant. By comparison, only 13 residues are involved in $A 2 / A 3$ contacts in both $\alpha_{\mathrm{O}}$ and $\alpha_{\mathrm{C}}$. Seven of these residues, or $54 \%$, are invariant and 6 of them are also involved in $A 2 / A 3$ interactions in $\alpha_{49}$ (T). If the conformation of the latter were a crystallization artifact, the fraction of invariant residues involved in its domain interactions would not be expected to be higher than the overall $36.4 \%$ identity among the four aligned sequences. Therefore, the high degree of residue conservation at the A2/A3 interface suggests a functional role for the $\alpha_{49 \text { (T) }}$ conformation. The invariant residues in Figure 6 are also highly conserved in an alignment of 7 bacterial and 13 archaeal ACS amino acid sequences (10).

The archaeal A-cluster-containing subunit resembles $\alpha_{49}$ in that it lacks the N-terminal $A 1$ domain. Therefore, it is remarkable that 16 of the 20 residues from $A 2$ and $A 3$ that interact with $A l$ in $\alpha_{C}$ are conserved in the ACS subunit of the ACDS complex from methanogens (Fig. 6). Doukov et al. noted structural similarities between a large fraction of domains $C 2$ and $C 4$ of $\mathrm{CODH}$ and the $A l$ domain of ACS in $\mathrm{CODH} / \mathrm{ACS}_{M o t}(4)$. The recently reported structure of the archaeal $M e b \mathrm{CODH}$ was found to be very similar to its bacterial counterparts, except for its $\mathrm{N}$ - and C-terminal regions and the presence of an extra FeS-cluster binding domain (7). Intrigued by these similarities, we performed a detailed comparison of the available structures (Table S1). We found that $A 1_{M o t}$ resembles more the archaeal CODH than the bacterial one. This is indicated by (i) a larger number of superimposed residues (285 vs. 217), (ii) a corresponding lower root-mean-square deviation (rmsd) of $\mathrm{C}_{\alpha}$-positions ( $2.23 \AA$ vs. $2.54 \AA$ ) and (iii) a higher percentage of sequence identities (16\% vs. $12 \%)$. When the superposition is carried out separately for two sub-domains of $A 1$, the statistics are further improved (Table S1). Furthermore, a DALI search (42) with $A 1_{M o t}$ gives a Z-score of 34.1 for the archaeal $\mathrm{CODH}$ subunit $\left(\mathrm{ACDS}_{\mathrm{Meb}}-\alpha\right)$, compared to a value of 20.8 for the bacterial one $\left(\mathrm{CODH}_{\mathrm{Mot}^{-}}\right.$ $\beta)$.

The bacterial ACS/CODH ${ }_{M o t} A l$ domain has a tunnel for $\mathrm{CO}$ diffusion between the $\mathrm{C}$ - and Aclusters and an equivalent tunnel is present in the superimposed archaeal CODH (Fig. 7). However, like the tunnel in $\alpha_{O}$, it does not reach the surface, being blocked by the helix that in $\mathrm{ACS}_{\mathrm{Mot}}$ acts as a tunnel gate, allowing a connection between the A- and C-clusters only in $\alpha_{C}(5,20)$. If we assume that the archaeal CODH domains that correspond to $C 2$ and $C 4$ of their 
bacterial counterparts have the same tunnel function as $\mathrm{ACS}_{M o t}$ domain $A 1$, the A-cluster in the superimposed ACDS-complex is positioned like in $\alpha_{C}$. Accordingly, the distance between the catalytic Ni ions in CODH and ACS would change from $66 \AA$ in the bacterial $\left(\alpha_{C}\right)$ enzyme complex to only about $34 \AA$ in its archaeal counterpart.

We have taken advantage of the high structural (Table S1, Fig. 7) and amino acid sequence similarities (Fig. 6) among domains of the bacterial and archaeal enzymes to model the relative position of CODH and ACS components in the ACDS complex (Fig. 8). Our model predicts that the smaller archaeal ACS interacts with the CODH C2/C4 domains as the bacterial $A 2 /$ $A 3$ domains interact with $\mathrm{ACS}_{M o t} A l$ (see also Fig. 4). The $\mathrm{C}_{\alpha}$-atom superposition of $\alpha_{C}$ domain

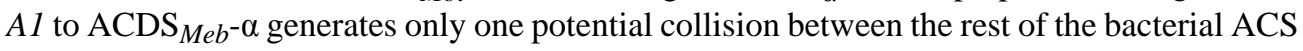
and the archaeal CODH. It involves Gly327, which aligns with Ser11 of the ACS subunit of ACDS (Fig. 6). However, only a small readjustment of the N-terminal region of the archaeal ACS would be required to remove this too short contact. Domain 1 of the archaeal ACS, which corresponds to $A 2$ in $\mathrm{ACS}_{M o t}$, would also interact with the C-terminal region of one of the CODH subunits (Fig. 8). Seven of the 16 residues at the Mot Al/A3 interface are invariant in the superimposed $\mathrm{ACDS}_{\mathrm{Meb}} \mathrm{CODH}$ structure, where they are exposed to solvent (see also Fig. S1). This $44 \%$ sequence identity is much higher than the overall value of $16 \%$ found for the 276 aligned residues (Table S1). Even more strikingly, these conserved residues establish 31 of the 41 contacts $\left(\mathrm{d}<3.8 \AA\right.$ ) between $A 1$ and $A 3$ in $\alpha_{\mathrm{C}}$. We conclude that the CODH-ACS portion of the ACDS complex shown in Fig. 8 is a plausible model for the "closed" form in which there is a continuous tunnel between the A- and C-clusters. Many short $(<2 \AA)$ contacts leading to van der Waals collisions are generated when similar superpositions are performed with either $\alpha_{\mathrm{O}}$ or $\alpha_{49(\mathrm{~T})}$. Thus, modeling of other putatively functional conformations of the CODH-ACS component of the ACDS complex is not possible with the currently available structures.

\section{DISCUSSION}

The structure of $\alpha_{49(\mathrm{~T})}$ reported here (Fig. 1) shows major differences with previous ACS structures, both in the metal composition of the A-cluster and in the arrangement of domains $A 2$ and $A 3$ (Fig. 2). Indeed, this is the first structure where the distal site of the A-cluster $\left(\mathrm{M}_{\mathrm{d}}\right)$ is not occupied by a Ni ion and is empty (Fig. 3). This does not prevent the tetrahedral binding of a metal ion heavier than $\mathrm{Ni}$ at the proximal labile $\mathrm{Ni}$ site $\left(\mathrm{M}_{\mathrm{p}}\right)$. In this respect $\alpha_{49(\mathrm{~T})}$ resembles the CODH/ACS ${ }_{\text {Mot }}$ "closed" structures, which show either tetrahedral Zn or $\mathrm{Cu}$ bound at the labile $\mathrm{Ni}_{\mathrm{p}}$ site. Since no metal ions were added during the crystallization experiments, the bound $\mathrm{Zn}$ or $\mathrm{Cu}$ ion must come from either the reagents or the cell extracts used for purification. In fact, the binding of $\mathrm{Zn}$ or $\mathrm{Cu}$ to the $\alpha_{49}$ subunit in cell extracts would explain why it cannot be activated by the addition of $\mathrm{NiCl}_{2}(14)$. Metal heterogeneity greatly complicates the interpretation of spectroscopic studies. In addition to the observed presence of $\mathrm{Ni}, \mathrm{Cu}$ and $\mathrm{Zn}$ at $\mathrm{M}_{\mathrm{p}}(4,5)$, the results reported here show that A-cluster heterogeneity might also arise from fractions with an empty $\mathrm{M}_{\mathrm{d}}$ site. Attempts to generate a $\mathrm{Ni}_{2} \mathrm{Fe}_{4} \mathrm{~S}_{4} \mathrm{~A}$-cluster by soaking crystals in $\mathrm{NiCl}_{2}$ solutions resulted in crystal cracking and/or loss of diffracting power. Nevertheless, manual model building suggests that only minor changes in the $\alpha_{49(\mathrm{~T})}$ structure would be necessary to incorporate $\mathrm{Ni}$ at the $\mathrm{M}_{\mathrm{p}}$ and $\mathrm{M}_{\mathrm{d}}$ sites. For the latter, a small rearrangement of the Cys595-Gly596-Cys597 loop would be required (Fig. 5B).

The high percentage of conserved residues between bacterial and archaeal enzymes at the A2/ $A 3$ domain interface (Fig. 6) suggests that the novel $\alpha_{49}$ (T) conformation, or a closely related one, may be functionally relevant. In terms of A-cluster accessibility, the new structure is intermediate between $\alpha_{C}$ and $\alpha_{O}$. In the former, the A-cluster is connected to the CO-producing C-cluster through a long hydrophobic tunnel. An accessibility analysis (not shown) indicates that in this conformation the active site cannot react with bulky substrates such as CoFeSP or 
CoA. We have postulated that $\alpha_{\mathrm{O}}$, in which the connection between the A- and C-clusters is blocked, may be the conformation that accepts a methyl group from $\operatorname{CoFeSP}(5,20)$.

Conversely, the novel $\alpha_{49 \text { (T }}$ could correspond to the conformation that binds CoA. Indeed, this idea is supported by i) the presence of tryptophan and arginine residues that could be protected from chemical modification by $\mathrm{CoA}$ in the cleft formed between domains $A 2$ and $A 3$ (Fig. 4); ii) the electrostatic complementarity between this region and CoA (Fig. 4C); and iii) the corresponding distribution of the adenine, pyrophosphate and cysteamine moieties of CoA relative to tryptophanes, arginines and the $\mathrm{M}_{\mathrm{p}}$ site of the A-cluster, respectively (Fig. 5A). Furthermore, in $\alpha_{49(\mathrm{~T})}$ His 408 is ideally positioned to abstract a proton from CoA-SH before its $\mathrm{S}^{-}$atom binds to $\mathrm{Ni}_{\mathrm{p}}$ (Fig. 5B). This is consistent with the prediction (43) that a base with a $\mathrm{pK}_{\mathrm{a}} \sim 6$ deprotonates CoA.

The structures of $\alpha_{C}$ and $\alpha_{O}$ contain another extensive positive patch on the surface of domain 1 (not shown), not far from the A-cluster, involving several arginine residues located around Trp151. According to the results of Shanmugasundaram et al. (40,41), this region could also bind CoA. However, in $\alpha_{\mathrm{C}}$ the A-cluster is buried in the protein and therefore not accessible for CoA, whereas in $\alpha_{\mathrm{O}}$ access of the cysteamine moiety of the coenzyme to the active site would be blocked by domain $A 3$, assuming binding of its adenine and pyrophosphate moieties to Trp151 and surrounding arginines. The binding mode of CoA is likely to be evolutionary conserved. Sequence comparisons (Fig. S1 and 10) show that this is not the case for the Trp151 surface region. On the other hand, several crucial residues of the $A 2 / A 3$ cleft are invariant: His408, proposed above to be involved in the deprotonation of CoA-SH, His419, to which His408 is hydrogen-bound (Fig. 5B), Trp427 and the nearby Arg334 and Arg429 (Fig. 5A). These could be the two arginines that are protected from chemical modification by CoA (41). In conclusion, the combination of a large number of observations strongly suggests the involvement of the $A 2 / A 3$ cleft in CoA binding.

Substantial ACS domain movements during catalysis would explain the reported relatively low rates of acetyl-CoA synthesis $\left(<10 \mathrm{~s}^{-1}\right)$. According to kinetic data, CoA binds to the Acluster after $\mathrm{CH}_{3}{ }^{+}$and $\mathrm{CO}(44,45)$. This makes sense in a scheme where these two substrates bind to the two available $\mathrm{Ni}_{\mathrm{p}}$ coordination sites prior to the migration/insertion reaction that results in acetyl synthesis and that liberates one coordination site for subsequent CoA binding. CoA does not bind to CO-treated ACS (43), suggesting that these two substrates might compete for the same binding site and/or that the enzyme conformation is not suitable for coenzyme binding. Similar chemistry involving the sequential binding of three substrates (methyl, CO and thiol) to a single nickel ion to produce a thioester has been reported for synthetic $\mathrm{Ni}$ (II) complexes (46). If our interpretation is correct $\mathrm{CH}_{3}{ }^{+}, \mathrm{CO}$ and $\mathrm{CoA}$ binding would require the enzyme to adopt conformations similar to $\alpha_{\mathrm{O}}, \alpha_{\mathrm{C}}$ and $\alpha_{49 \text { (T }}$, respectively. In $\alpha_{49 \text { (T }}$, two $A 2$ conserved residues, $\mathrm{Arg} 405$ and His408, could respond to changes at the active site and trigger domain movements towards other enzyme conformations (Fig. 3,5D and 5E). The order of $\mathrm{CH}_{3}{ }^{+}$and $\mathrm{CO}$ binding during catalysis is still controversial $(44,45)$. If $\mathrm{CH}_{3}{ }^{+}$were to bind $\mathrm{Ni}_{\mathrm{p}}$ before $\mathrm{CO}$, a more open $\alpha_{\mathrm{C}}$ conformation would be needed to prevent the collision of the bound methyl group with the enzyme (20). Structures of enzyme-substrate complexes and reaction intermediates will be required to determine whether additional conformational changes take place during catalysis. It appears that protein domain movements finely modulate substrate accessibility to the A-cluster by generating suitable interacting surfaces (Fig. 4).

Archaeal ACS shows extensive amino acid sequence similarities with $A 2$ and $A 3$ from the bacterial enzyme (Fig. 6). However, the absence of $A l$ in the former implies that the tunnel network between the C- and A-clusters of archaeal ACDS must be different from the one found in bacterial CODH/ACS. Suitable candidates for replacing the tunnel section of bacterial AI are two tunnel-containing domains in the $\mathrm{CODH}$ portion of a recent $\mathrm{ACDS}_{\mathrm{Meb}^{-}-\alpha_{2} \varepsilon_{2}}$ crystal structure (7). These domains can be superimposed to more than $90 \%$ of sub-domains $A l_{a}$ and 
$A 1_{b}$ (Fig. 7,Table S1). Drennan et al. have reported a similar fold for the bacterial $\mathrm{CODH}_{M o t}$ domains $C 2$ and $C 4$ (4), but their resemblance to $A l$ is less extensive (Table S1) and they do not contain a tunnel. Although a tunnel is present in the same domains in mono-functional CODHs of CO-oxidizing bacteria $(47,48)$, their similarity to $A 1$, reflected by DALI Z-scores (42) of about 20, are comparable to the value found for the Mot enzyme. This Z-score is much lower than the value of 34.1, obtained when $A l$ and the archaeal Meb CODH are compared. Moreover, more than $75 \%$ of the residues involved in contacts between $A 1$ and $A 3$ in Mot $\alpha_{C}$ are conserved in the aligned sequences of the archaeal domains (Fig. 6 and S1). All these similarities suggest a plausible model for the CODH/ACS interaction in archaeal ACDS that includes a continuous tunnel for $\mathrm{CO}$ diffusion between the two active sites, obtained by superposition of $A l$ from $M o t \alpha_{C}$ to $C 2$ and $C 4$ of $\mathrm{CODH}_{M e b}$ (Fig. 7).

In the obtained partial model of the ACDS complex (Fig. 8), all the [4Fe-4S] centers of the archaeal CODH are more than $45 \AA$ away from the A-cluster, indicating that there is no direct electron transfer between the two enzymes. Consequently, the reductive activation of the Acluster should require, like in the bacterial CODH-ACS complex, an external electron source (see also 49). Ferredoxin (Fd) may be the redox partner that activates both bacterial and archaeal enzyme complexes by two successive one-electron reductions $(11,50)$. It is noteworthy that an Al region of $\mathrm{CODH} / \mathrm{ACS}_{\mathrm{Mot}}$ that lies close to the A-cluster and that can be cross-linked with $\mathrm{Fd}(51)$ is also accessible in the corresponding $C 4$ region in our partial model of ACDS.

$\mathrm{Ni}$-containing CODH and ACS are considered to be ancient enzymes originally involved in primordial anaerobic carbon fixation pathways (52). Their occurrence in both bacteria and archaea may imply that they were already present in the Last Universal Common Ancestor (LUCA), but horizontal gene transfer is also a possibility. Domains $C 2$ and $C 4$ (bacterial $M o t$ enzyme nomenclature) are found in bacterial and archaeal CODH's and hybrid cluster proteins (HCP's) $(53,54)$ and in $A l$ from bacterial ACS (Fig. 8). The $C 2$ domain is involved in extensive contacts with its counterpart in all CODH homo-dimers, and it has similar contacts with a homologous domain in monomeric HCP's (Fig. S2). In CODH's and HCP's there is an additional domain $C 3$ that is related to $C 4$ by pseudo two-fold symmetry (Fig. 8, Fig. S2). A metal-containing active site is bound at the interface of these two domains: the C-cluster in $\mathrm{CODH}$ and the hybrid cluster in HCP. Domains $C 2$ and $C 4$ may have originated from a common monomeric ancestral protein of unknown function, possibly binding a simpler metal site. The bacterial ACS domain $A l$ lacks $C 3$ and, consequently, it is not suited to coordinate a metal cluster. However, it is remarkable that its structural similarity to the archaeal CODH $C 2$ and C4 domains is comparable to that of the latter to the corresponding bacterial CODH domains (Table S1). Another common feature of CODH, HCP and bacterial ACS is the presence of a tunnel segment at the $C 2 / C 4$ interface $\left(A l_{a} / A 1_{b}\right.$ in ACS, see Fig. 8 and S2). In all these enzymes, except $\mathrm{CODH}_{M o t}$, the tunnel continues for an equivalent distance in $C 4$. In $\mathrm{CODH}_{M o t}$ the tunnel extends inside $A l$ instead.

Taken together, our results suggest that bacterial ACS originated from the duplication of the DNA region coding for archaeal CODH $C 2$ and $C 4$ domains (generating $A 1$ ) and its fusion to the archaeal ACS gene, consisting of domains $A 2$ and $A 3$. This modification would have allowed for the release of ACS activity from the multi-enzymatic ACDS methanogenic complex. In this scenario the archaeal enzymes existed before the bacterial ones (see also 55). The $A l$-containing ACS in the CO-tolerant anaerobic thermophilic bacterium $C$.

hydrogenoformans is a monomer under high $\mathrm{CO}$ concentrations, but associates with $\mathrm{CODH}-$ III when CO levels are low. This ACS/CODH-III complex, very similar to its counterpart in the acetogenic Mot, is postulated to be involved in the Wood-Ljungdahl pathway of $\mathrm{CO}_{2}$ fixation (56). Upon evolution of the acetogenic CODH/ACS complex, most of the tunnel function of the $\mathrm{CODH} C 4$ domain disappeared, presumably to prevent escape of $\mathrm{CO}$. This is 
different from the situation in the archaeal ACDS multi-enzyme complex where some CO leakage has been observed (57).

\section{CONCLUSIONS}

The domain rearrangement found in truncated ACS adds important new information on how protein movements may control the complex catalytic mechanism of acetyl-CoA synthesis. Previously determined closed and open ACS structures appear well suited to bind CO and $\mathrm{CH}_{3}{ }^{+}$, respectively. Several lines of evidence suggest that the truncated ACS structure reported here is closely related to the conformation that binds the third substrate, CoA. Further studies, including mutagenesis of selected residues, will be required to establish whether this is indeed the case. The truncated ACS structure has also been used to put forward a scenario for the evolutionary origin of the bacterial ACS from the archaeal ACDS complex.

\section{Supplementary Material}

Refer to Web version on PubMed Central for supplementary material.

\section{Acknowledgments}

We thank the staff of the BM30A beamline of the ESRF for their help with X-ray data collection.

\section{Abbreviations}

$\begin{array}{ll}\text { ACS } & \text { acetyl-CoA synthase } \\ \text { ACDS } & \text { acetyl-CoA decarbonylase/synthase } \\ \text { Ch } & \text { Carboxydothermus hydrogenoformans } \\ \text { CoA } & \text { coenzyme A } \\ \text { CoFeSP } & \text { corrinoid iron-sulfur protein } \\ \text { CODH } & \text { carbon monoxide dehydrogenase } \\ \text { HCP } & \text { hybrid cluster protein } \\ \text { Meb } & \text { Methanosarcina barkeri } \\ \text { Met } & \text { Methanosarcina thermophila } \\ \text { Mot } & \text { Moorella thermoacetica }\end{array}$

\section{References}

1. Fontecilla-Camps, JC.; Volbeda, A. CO dehydrogenase / acetyl CoA synthase. In: Messerschmidt, A., editor. Handbook of Metalloproteins. Vol. online edition. John Wiley \& Sons; 2008. p. 1-16.DOI: 10.1002/0470028637.met212

2. Ljungdahl LG. The autotrophic pathway of acetate synthesis in acetogenic bacteria. Annu. Rev. Microbiol 1986;40:415-450. [PubMed: 3096193]

3. Wood HG. Life with $\mathrm{CO}$ or $\mathrm{CO}_{2}$ and $\mathrm{H}_{2}$ as a source of carbon and energy. FASEB J 1991;5:156-163. [PubMed: 1900793]

4. Doukov TI, Iverson TM, Seravalli J, Ragsdale SW, Drennan CL. A Ni-Fe-Cu center in a bifunctional carbon monoxide dehydrogenase/acetyl-CoA synthase. Science 2002;298:567-572. [PubMed: 12386327]

5. Darnault C, Volbeda A, Kim EJ, Legrand P, Vernède X, Lindahl PA, Fontecilla-Camps JC. Ni-Zn$\left[\mathrm{Fe}_{4}-\mathrm{S}_{4}\right]$ and $\mathrm{Ni}-\mathrm{Ni}-\left[\mathrm{Fe}_{4}-\mathrm{S}_{4}\right]$ clusters in closed and open $\alpha$ subunits of acetyl-CoA synthase/carbon monoxide dehydrogenase. Nat. Struct. Biol 2003;10:271-279. [PubMed: 12627225] 
6. Jeoung J-H, Dobbek H. Carbon dioxide activation at the Ni,Fe-cluster of anaerobic carbon monoxide dehydrogenase. Science 2007;318:1461-1464. [PubMed: 18048691]

7. Gong W, Hao B, Wei Z, Ferguson DJ, Tallant T, Krzycki JA, Chan MK. Structure of the $\alpha_{2} \varepsilon_{2} \mathrm{Ni}$ dependent CO dehydrogenase component of the Methanosarcina barkeri acetyl-Co decarbonylase/ synthase complex. Proc. Natl. Acad. Sci. U.S.A 2008;105:9558-9563. [PubMed: 18621675]

8. Volbeda A, Fontecilla-Camps JC. Structural bases for the catalytic mechanism of Ni-containing carbon monoxide dehydrogenases. Dalton Trans 2005;21:3443-3450. [PubMed: 16234923]

9. Svetlitchnyi V, Dobbek H, Meyer-Klaucke W, Meins T, Thiele B, Romer P, Huber R, Meyer O. A functional Ni-Ni-[4Fe-4S] cluster in the monomeric acetyl-CoA synthase from Carboxydothermus hydrogenoformans. Proc. Natl. Acad. Sci. U.S.A 2004;101:446-451. [PubMed: 14699043]

10. Lindahl, PA.; Graham, DE. Acetyl-coenzyme A synthases and nickel-containing carbon monoxide dehydrogenases. In: Sigel, A.; Sigel, H.; Sigel, RKO., editors. Nickel and its surprising impact in nature, Vol. 2 of Metal ions in life sciences. John Wiley \& Sons, Ltd.; Chichester, UK: 2007. p. 357-416.

11. Ragsdale SW, Pierce E. Acetogenesis and the Wood-Ljungdahl pathway of $\mathrm{CO}_{2}$ fixation. Biochem. Biophys. Acta 2008;1784:1873-1898. [PubMed: 18801467]

12. Barondeau DP, Lindahl PA. Methylation of carbon monoxide dehydrogenase from Clostridium thermoaceticum and mechanism of acetyl coenzyme A synthesis. J. Am. Chem. Soc 1997;119:39593970.

13. Menon S, Ragsdale SW. Role of the $[4 \mathrm{Fe}-4 \mathrm{~S}]$ cluster in reductive activation of the cobalt center of the corrinoid iron-sulfur protein from Clostridium thermoaceticum during acetate biosynthesis. Biochemistry 1998;37:5689-5698. [PubMed: 9548955]

14. Loke HK, Tan XS, Lindahl PA. Genetic construction of truncated and chimeric metalloproteins derived from the $\alpha$ subunit of acetyl-CoA synthase from Clostridium thermoaceticum. J. Am. Chem. Soc 2002;124:8667-8672. [PubMed: 12121109]

15. Gencic S, Grahame DA. Nickel in subunit $\beta$ of the acetyl-CoA decarbonylase/synthase multienzyme complex in methanogens: Catalytic properties and evidence for a binuclear Ni-Ni site. J. Biol. Chem 2003;278:6101-6110. [PubMed: 12464601]

16. Gu W, Gencic S, Cramer SP, Grahame DA. The A-cluster in subunit $\beta$ of the acetyl-CoA decarbonylase/synthase complex from Methanosarcina thermophila: Ni and Fe K-edge XANES and EXAFS analyses. J. Am. Chem. Soc 2003;125:15343-15351. [PubMed: 14664578]

17. Funk T, Gu W, Friedrich S, Wang H, Gencic S, Grahame DA, Cramer SP. Chemically distinct Ni sites in the A-cluster in subunit $\beta$ of the acetyl-CoA decarbonylase/synthase complex from Methanosarcina thermophila: Ni L-edge absorption and X-ray magnetic circular dichroism analyses. J. Am. Chem. Soc 2004;126:88-95. [PubMed: 14709073]

18. Grahame DA, DeMoll E. Partial reactions catalyzed by the protein components of the acetyl-CoA decarbonylase/synthase enzyme complex from Methanosarcina barkeri. J. Biol. Chem 1996;271:8352-8358. [PubMed: 8626532]

19. Doukov TI, Blasiak LC, Seravalli J, Ragsdale SW, Drennan CL. Xenon in and at the end of the tunnel of bifunctional carbon monoxide dehydrogenase/ acetyl-CoA synthase. Biochemistry 2008;47:34743483. [PubMed: 18293927]

20. Volbeda A, Fontecilla-Camps JC. Crystallographic evidence for a $\mathrm{CO} / \mathrm{CO}_{2}$ tunnel gating mechanism in the bifunctional carbon monoxide dehydrogenase/acetyl coenzyme A synthase from Moorella thermoacetica. J. Biol. Inorg. Chem 2004;9:525-532. [PubMed: 15221479]

21. Vernède X, Fontecilla-Camps JC. A method to stabilize reduced and/or gas-treated protein crystals by flash-cooling under a controlled atmosphere. J. Appl. Crystallogr 1999;32:505-509.

22. Diederichs K, McSweeney S, Ravelli RB. Zero-dose extrapolation as part of macromolecular synchrotron data reduction. Acta Cryst 2003;D59:903-909.

23. Kabsch, W. International tables for crystallography, Vol. F. Crystallography of Biological Macromolecules. Rossmann, MG.; Arnold, E., editors. Kluwer Academic Publishers; Dordrecht: 2001. p. 218-225.

24. Read RJ. Pushing the boundaries of molecular replacement with maximum likelihood. Acta Cryst 2001;D57:1373-1382. 
25. Storoni LC, McCoy AJ, Read RJ. Likelihood-enhanced fast rotation functions. Acta Cryst 2004;D60:432-438.

26. McCoy AJ, Grosse-Kunstleve RW, Storoni LC, Read RJ. Likelihood-enhanced fast translation functions. Acta Cryst 2005;D61:458-464.

27. Murshudov GN, Vagin AA, Dodson EJ. Refinement of macromolecular structures by the maximumlikelihood method. Acta Cryst 1997;D53:240-255.

28. Collaborative Computational Project Number 4. The CCP4 suite: programs for protein crystallography. Acta Cryst 1994;D50:760-763.

29. Winn MD, Isupov MN, Murshudov GN. Use of TLS parameters to model anisotropic displacements in macromolecular refinement. Acta Cryst 2001;D57:122-133.

30. Roussel, A.; Cambillaud, C. Silicon Graphics Geometry Partners Directory. Vol. 81. Silicon Graphics Corp; Mountain View, USA: 1991. The Turbo-Frodo graphics package.

31. Chabrière E, Volbeda A, Fontecilla-Camps JC, Roth M, Charon MH. Combination of methods used in the structure solution of pyruvate:ferredoxin oxidoreductase from two crystal forms. Acta Cryst 1999;D55:1546-1554.

32. Kraulis PJ. MOLSCRIPT: a program to produce both detailed and schematic plots of protein structures. J. Appl. Cryst 1991;24:946-950.

33. Merritt EA, Bacon DJ. Raster3D: photorealistic molecular graphics. Meth. Enzymol 1997;277:505, 524. [PubMed: 18488322]

34. Lawrence MC, Bourke P. CONSCRIPT: a program for generating electron density isosurfaces for presentation in protein crystallography. J. Appl. Cryst 2000;33:990-991.

35. Baker NA, Sept D, Joseph S, Holst MJ, McCammon JA. Electrostatics of nanosystems: application to microtubules and the ribosome. Proc. Natl. Acad. Sci. USA 2001;98:10037-10041. [PubMed: 11517324]

36. Dolinsky TJ, Nielsen JE, McCammon JA, Baker NA. PDB2PQR: an automated pipeline for the setup, execution, and analysis of Poisson-Boltzmann electrostatics calculations. Nucl. Ac. Res 2004;32:W665-W667.

37. Ponder JW, Case DA. Force fields for protein simulations. Adv. Prot. Chem 2003;66:27-85.

38. Bas DC, Rogers DM, Jensen JH. Very fast prediction and rationalization of $\mathrm{pK}_{\mathrm{a}}$ values for proteinligand complexes. Proteins 2008;73:765-783. [PubMed: 18498103]

39. Keire DA, Robert JM, Rabenstein DL. Microscopic protonation equilibria and solution conformations of Coenzyme A and Coenzyme A disulfides. J. Org. Chem 1992;57:4427-4431.

40. Shanmugasundaram T, Kumar GK, Wood HG. Involvement of tryptophan residues at the Coenzyme A binding site of carbon monoxide dehydrogenase from Clostridium thermoaceticum. Biochemistry 1988;27:6499-6503. [PubMed: 3219350]

41. Shanmugasundaram T, Kumar GK, Shenoy BC, Wood HG. Chemical modification of the functional arginine residues of carbon monoxide dehydrogenase from Clostridium thermoaceticum. Biochemistry 1989;28:7112-7116. [PubMed: 2819052]

42. Holm L, Käärliäinen S, Rosenström P, Schenkel A. Searching protein structure bases with DaliLite v.3. Bioinformatics 2008;24:2780-2781. [PubMed: 18818215]

43. Wilson BE, Lindahl PA. Equilibrium dialysis study and mechanistic implications of coenzyme A binding to acetyl coenzyme A synthase/carbon monoxide dehydrogenase from Clostridium thermoaceticum. J. Biol. Inorg. Chem 1999;4:742-748. [PubMed: 10631605]

44. Tan X, Surovtsev IV, Lindahl PA. Kinetics of CO insertion and acetyl group transfer steps and a model of the acetyl coenzyme A synthase catalytic mechanism. J. Am. Chem. Soc 2007;128:1233112338. [PubMed: 16967985]

45. Seravalli J, Ragsdale SW. Pulse-chase studies of the synthesis of acetyl-CoA by carbon monoxide dehydrogenase/acetyl-CoA synthase. J. Biol. Chem 2008;283:8384-8394. [PubMed: 18203715]

46. Stavropoulos P, Muetterties MC, Carrié M, Holm RH. Structural and reaction chemistry of nickelcomplexes in relation to carbon-monoxide dehydrogenase - a reaction system simulating acetylcoenzyme-A synthase reactivity. J. Am. Chem. Soc 1991;113:8485-8492.

47. Dobbek H, Svetlitchnyi V, Gremer L, Huber R, Meyer O. Crystal structure of a carbon monoxide dehydrogenase reveals a [Ni-4Fe-5S] cluster. Science 2001;293:1281-1285. [PubMed: 11509720] 
48. Drennan CL, Heo J, Sintchak MD, Schreiter F, Ludden PW. Life on carbon monoxide: X-ray structure of Rhodospirillum rubrum Ni-Fe-S carbon monoxide dehydrogenase. Proc. Natl. Acad. Sci. U.S.A 2001;98:11973-11978. [PubMed: 11593006]

49. Maynard EL, Tan X, Lindahl PA. Autocatalytic activation of acetyl-CoA synthase. J. Biol. Inorg. Chem 2004;9:316-322. [PubMed: 15015040]

50. Gencic S, Grahame DA. Two separate one-electron steps in the reductive activation of the A cluster in subunit $\beta$ of the ACDS complex in Methanosarcina thermophila. Biochemistry 2008;47:55445555. [PubMed: 18442256]

51. Shanmugasundaram T, T. Wood HG. Interaction of ferredoxin with carbon monoxide dehydrogenase from Clostridium thermoaceticum. J. Biol. Chem 1992;267:897-900. [PubMed: 1730678]

52. Russell MJ, Martin W. The rocky roots of the acetyl-CoA pathway. Trends Biochem. Sci 2004;29:358-363. [PubMed: 15236743]

53. Cooper SJ, Garner CD, Hagen WR, Lindley PF, Bailey S. Hybrid-Cluster Protein (HCP) from Desulfovibrio vulgaris (Hildenborough) at $1.6 \AA$ resolution. Biochemistry 2000;39:15044-15054. [PubMed: 11106482]

54. Aragão D, Mitchell EP, Frazão CF, Carrondo MA, Lindley PF. Structural and functional relationships in the hybrid cluster protein family: structure of the anaerobically purified hybrid cluster protein from Desulfovibrio vulgaris at 1.35 A resolution. Acta Cryst 2008;D64:665-674.

55. Lindahl PA, Chang B. The evolution of acetyl coenzyme A synthase. Orig. Life Evol. Biosph 2001;31:403-434. [PubMed: 11599178]

56. Wu M, Ren Q, Durkin AS, Daugherty SC, Brinkac LM, Dodson RJ, Madupu R, Sullivan SA, Kolonay JF, Nelson WC, Tallon LJ, Jones KM, Ulrich LE, Gonzalez JM, Zulin IB, Robb FT, Eisen JA. Life in hot carbon monoxide: the complete genome sequence of Carboxydothermus hydrogenoformans Z-2901. Plos Genet 2005;1:563-574.

57. Eikmann B, Fuchs G, Thauer RK. Formation of carbon monoxide from $\mathrm{CO}_{2}$ and $\mathrm{H}_{2}$ by methanobacterium thermoautotrophicum. Eur. J. Biochem 1983;146:149-154. 


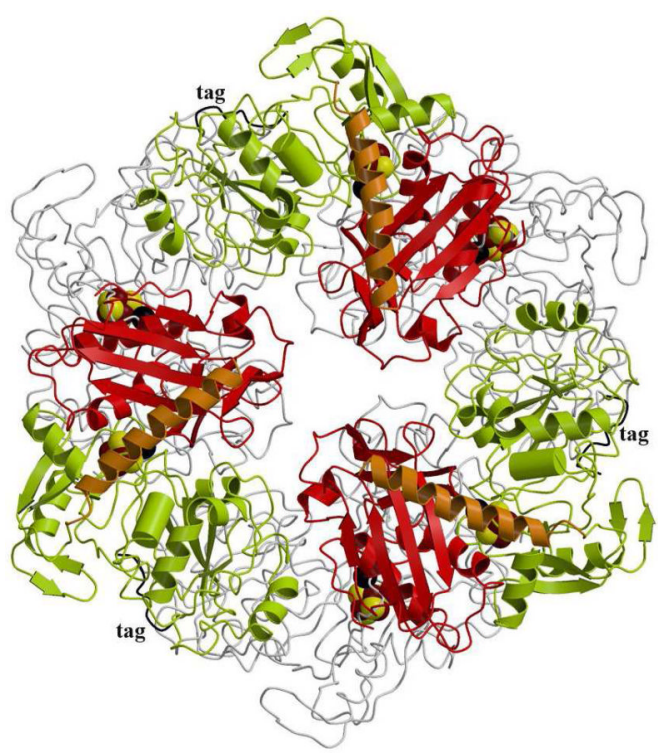

A

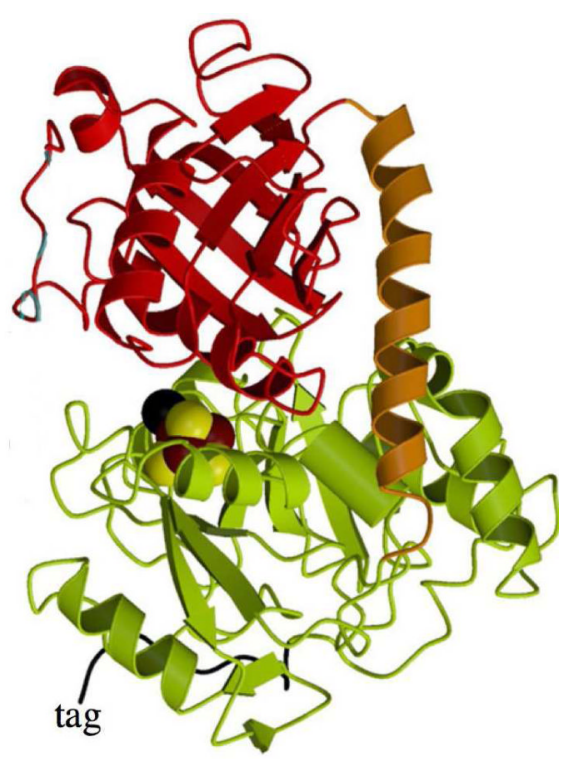

B

Figure 1.

Polypeptide fold of $\alpha_{49}$ in the new $\alpha_{49}$ (T) conformation. (A) Hexamer. (B) Monomer. Domain $A 2$ is shown in red, domain $A 3$ in lime green, the connecting $\alpha$-helix in orange and the Cterminal His-tag in black. A-cluster atoms are depicted as brown (Fe), yellow (S) and black $\left(\mathrm{Zn}\right.$ or $\mathrm{Cu}$ ) spheres. The bottom trimer in $(\mathbf{A})$ is shown as a grey $\mathrm{C}_{\alpha}$-trace. 

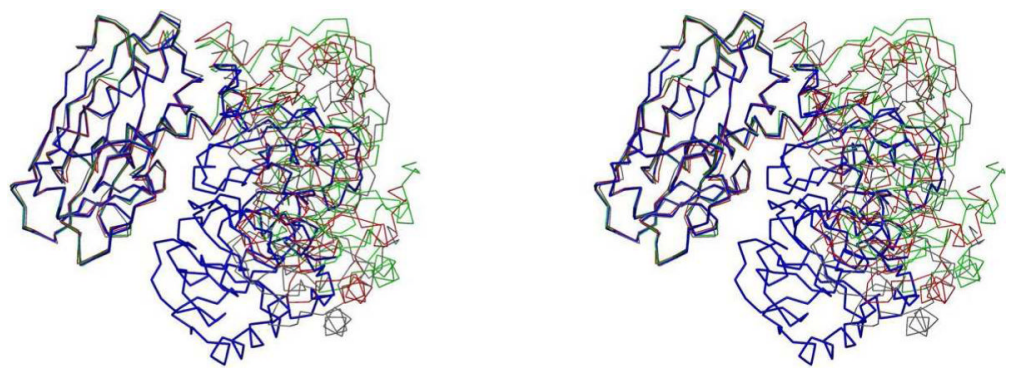

Figure 2.

Stereo image of ACS C $\alpha_{\alpha}$-backbone superposition of Mot $\alpha_{49(\mathrm{~T})}$ (blue), $\alpha_{\mathrm{O}}$ (green) and $\alpha_{\mathrm{C}}$ (red) and of $C h \alpha_{\mathrm{O}}$ (grey) to domain $A 2$, excluding domain $A 1$. 

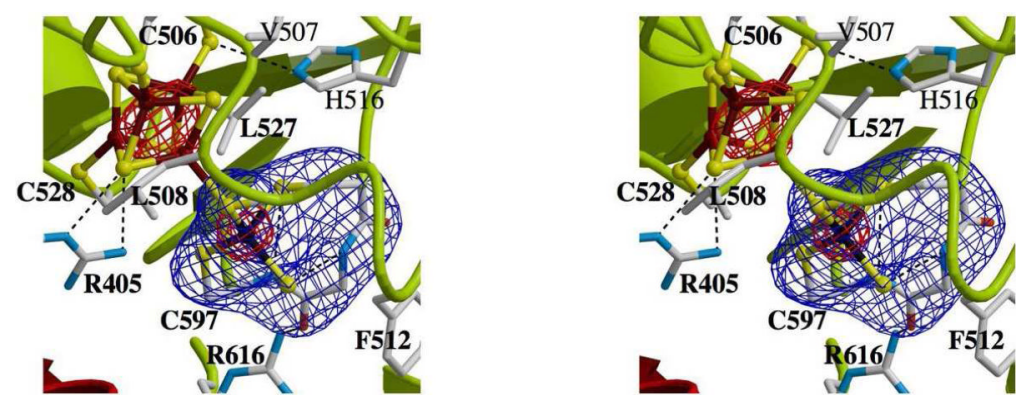

Figure 3.

Stereo image of the active site in $\alpha_{49}(\mathrm{~T})$. The blue grid depicts a six-fold averaged $\mathrm{F}_{\mathrm{O}}-\mathrm{F}_{\mathrm{c}}$ electron density map with the metal site next to the [4Fe-4S] cluster and its protein ligands (Cys509C $\beta$ and $\mathrm{S} \gamma, \mathrm{Cys595C} \alpha$ to $\mathrm{Cys} 597 \mathrm{~S} \gamma$ ) omitted from the phase and structure factor calculations. The red grid corresponds to a six-fold averaged $3.0 \AA$ A resolution anomalous difference map. 

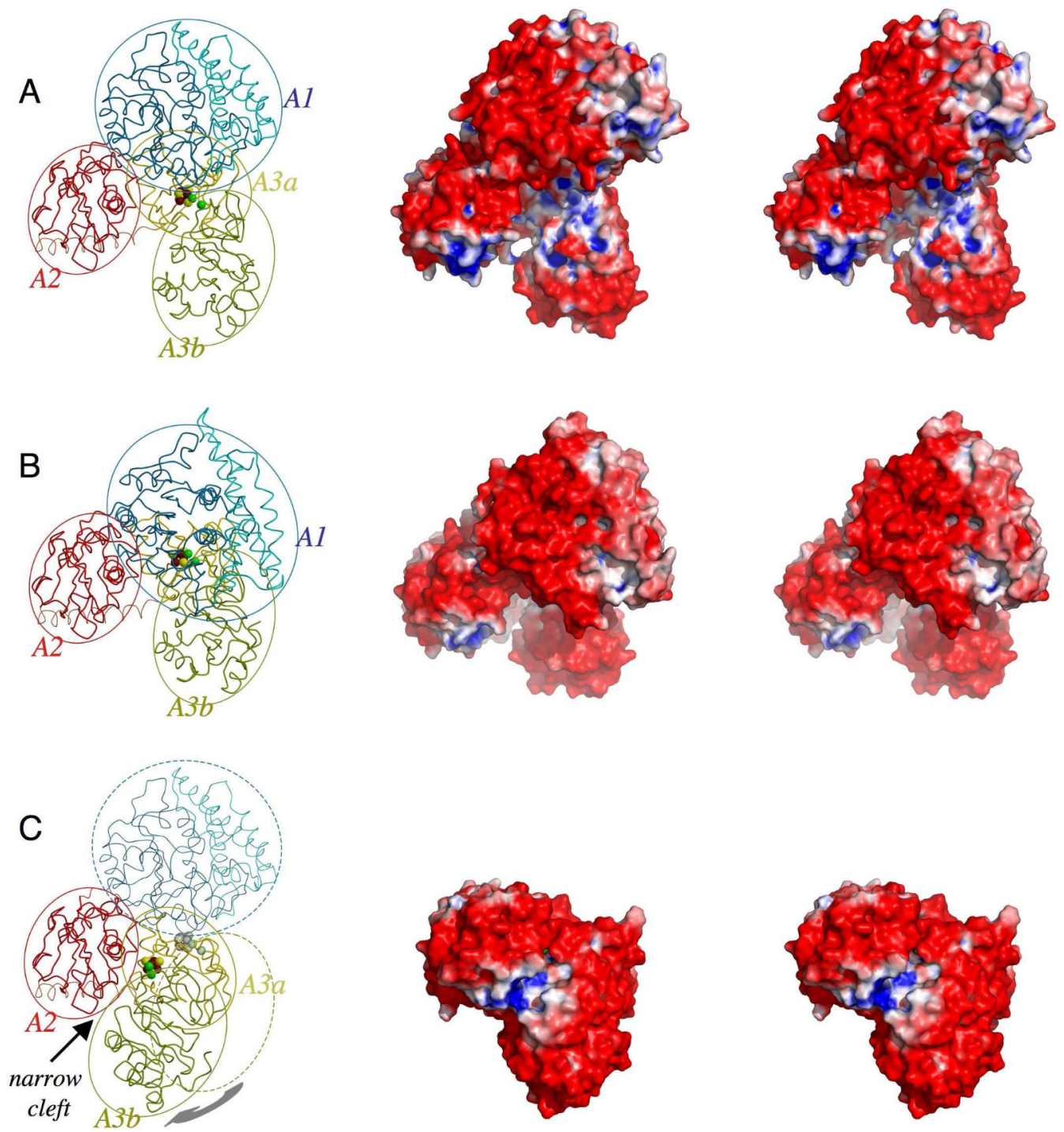

Figure 4.

Relative domain movements and stereo images of electrostatic potential surfaces of three $\mathrm{ACS}_{M o t}$ structures after superposition of their respective $A 2$ domains. (A) $\alpha_{\mathrm{o}} ;$ (B) $\alpha_{\mathrm{c}} ;$ (C) $\alpha_{49(\mathrm{~T})}$. Domains are shown as thin ribbons and they are labeled $A 1, A 2, A 3 a$ and $A 3 b$, with dashed ellipsoids showing their positions in $\alpha_{0}$. In (C) the hypothetical position of $A l$ is depicted in light blue, with the A-cluster position in $\alpha_{0}$ shown in semi-transparent mode. Color code of the electrostatic potential surfaces: red negative, blue positive. 


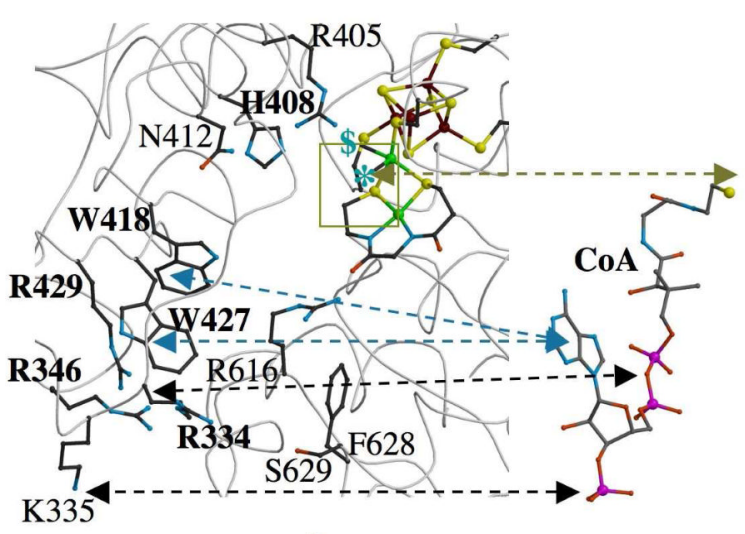

A

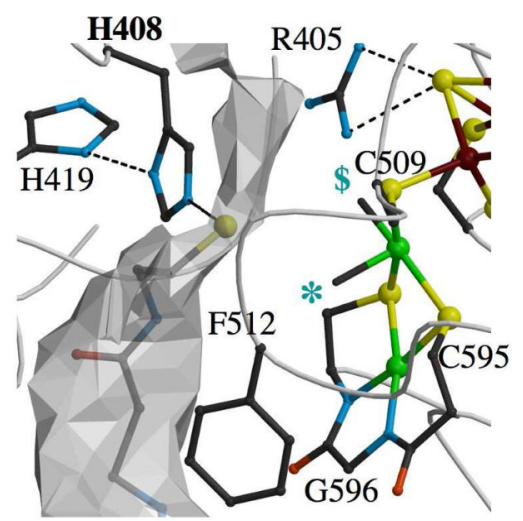

B

Figure 5.

Possible interactions of CoA with the narrow cleft formed in $\alpha_{49}(\mathrm{~T})$. (A) Arrows indicate the overall complementarity between moieties of CoA (structure taken from pdb deposition 1I12) and putatively protected amino acid residues and reacting metals in the cleft: they connect the 3'-phosphate with K335, adenine with W418/W427, pyrophosphate with R334/R346/R429 and the thiol with $\mathrm{Ni}_{\mathrm{p}}$ of the A-cluster. (B) Tentative docking of the cysteamine tail of CoA close to the A-cluster in $\alpha_{49}$ (T) inside a cavity map calculated for an accessible probe radius of $1.4 \AA$. Apical and equatorial substrate binding sites of the $\mathrm{A}$-cluster $\mathrm{Ni}_{\mathrm{p}}$ ion (taken from the superimposed $A 3$ structure of $\alpha_{\mathrm{o}}$ ) are labeled with * and $\$$, respectively. 


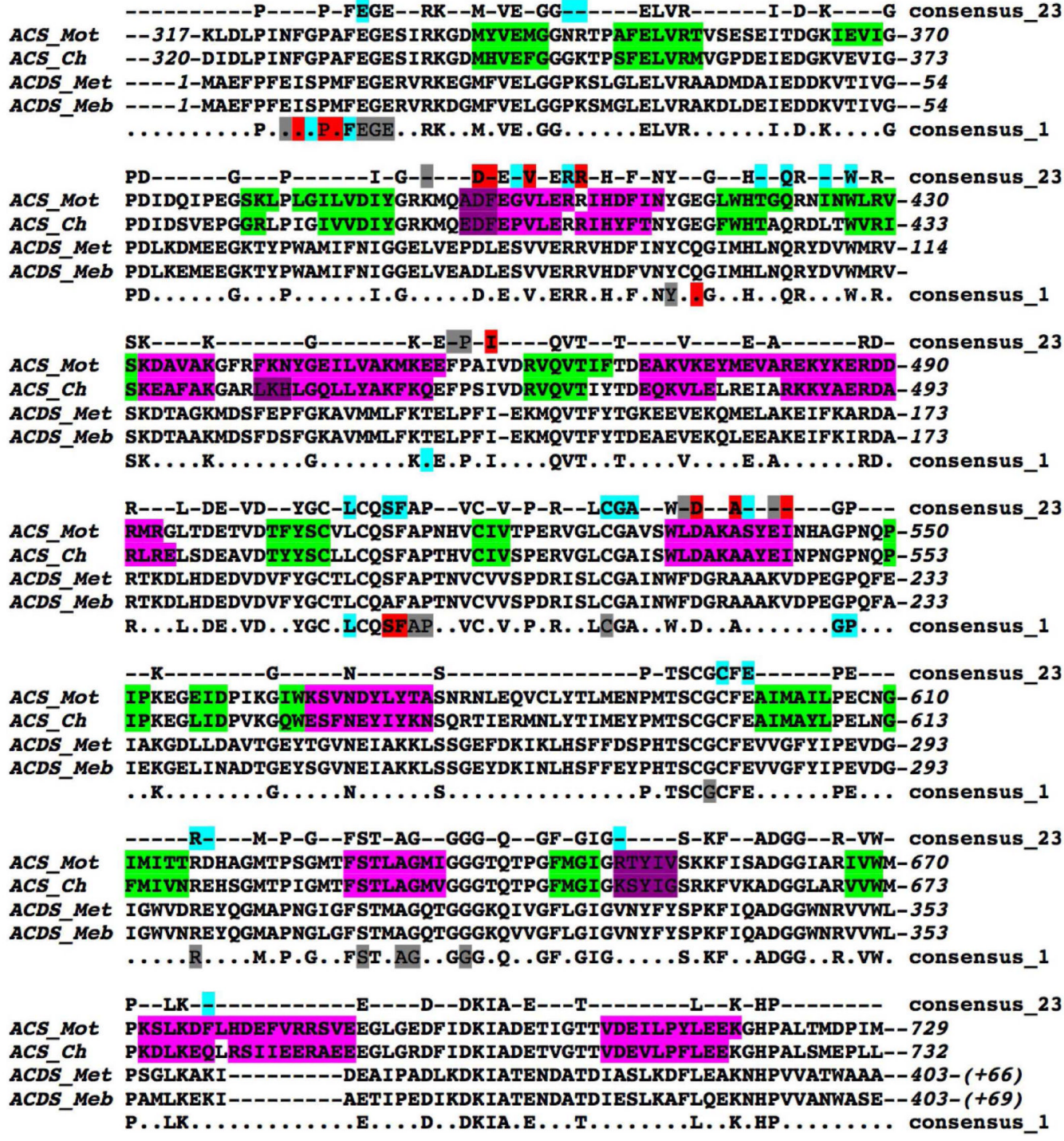

Figure 6.

Sequence alignment of bacterial and archaeal ACS's. The consensus_23 line highlights residues that are involved in close interactions ( $<3.8 \AA$ ) between Mot domains $A 2$ and $A 3$; colors: grey in $\alpha_{\mathrm{C}}$ and/or $\alpha_{\mathrm{O}}$, blue in $\alpha_{49(\mathrm{~T})}$, red in all three structures. The consensus_1 line does the same for interactions with Mot domain Al: grey in $\alpha_{\mathrm{C}}$, blue in $\alpha_{\mathrm{O}}$, red in both. Color codes in sequences: $\beta$-strands green, $\alpha$-helices pink, $3_{10}$-helices violet. 

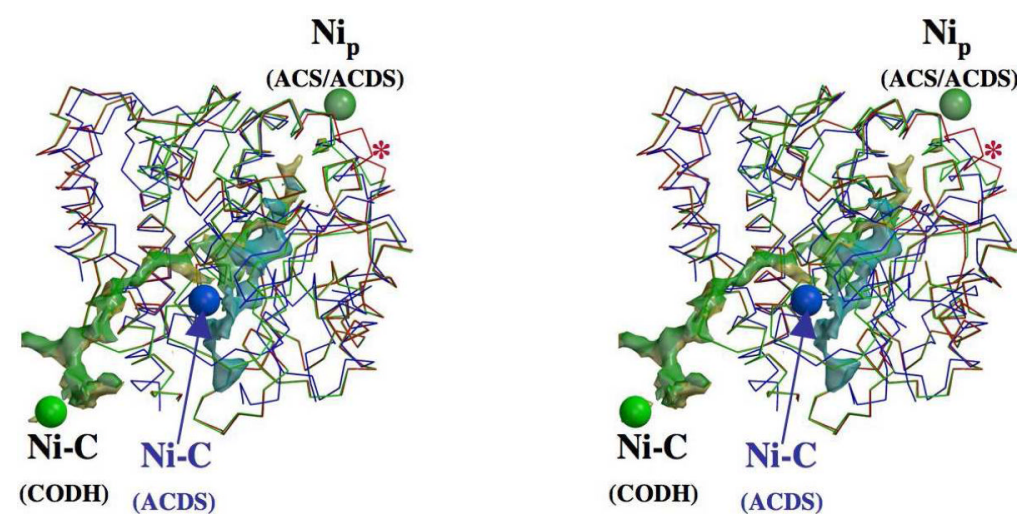

Figure 7.

Superposition of the $\mathrm{C}_{\alpha}$-backbone of $A l$ of $\mathrm{ACS}_{M o t} \alpha_{\mathrm{C}}$ (red) and $\alpha_{\mathrm{O}}$ (green) with domains $C 2$ and $C 4$ (using the bacterial CODH domain numbering) of $\operatorname{ACDS}_{M e b}$ (blue). Corresponding tunnels are shown in yellow, green and light-blue, respectively. $\mathrm{Ni}_{\mathrm{p}}$ indicates the location of the catalytic $\mathrm{Ni}$ ion of the A-cluster in $\alpha_{\mathrm{C}}$, the * highlights the nearby flexible helix. Ni-C shows the $\mathrm{Ni}$ position in the CODH C-cluster. 


\section{Bacteria}

Figure 8.

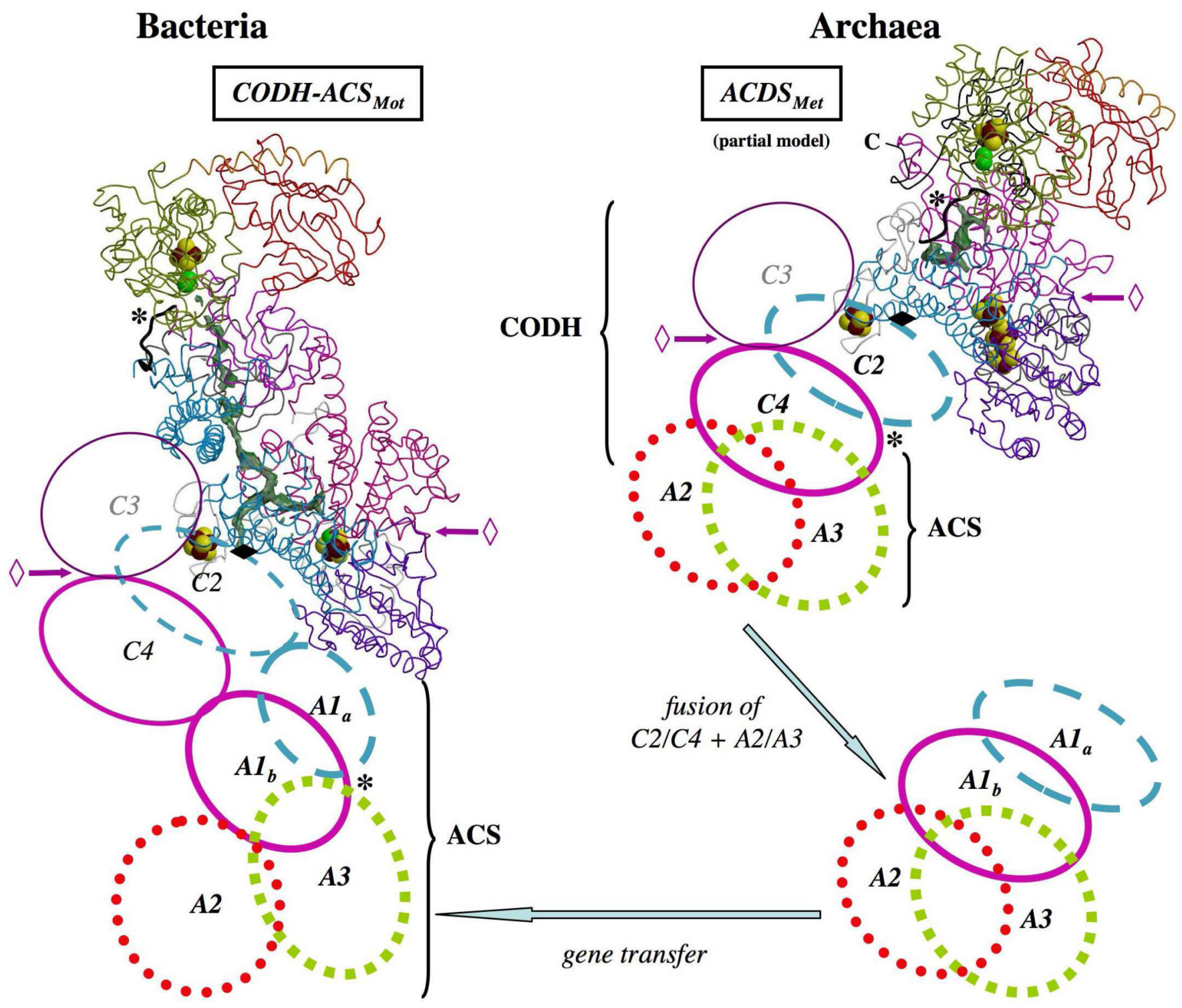

Proposed evolutionary relationship of ACS in bacteria and archaea, based on structural comparisons. A tentative model of the complex of the CODH and ACS in the archaeal $\mathrm{ACDS}_{M e b}$ is shown with domains numbered as in the bacterial complex. Two of the subunits are shown as $\mathrm{C}_{\alpha}$-traces, using different colors for the various domains. The latter are depicted as ellipses in the other, two-fold-symmetry-related subunits. Cluster locations in the top subunits are shown, excluding the D-cluster, which is located on the two-fold axis (indicated by a closed diamond) that relates subunits; hydrophobic tunnels are depicted in green; asterisks indicate potential ferredoxin binding sites; the C-terminus of one CODH subunit of ACDS is labeled with " $C$ "; the open diamond indicates a pseudo two-fold symmetry between $C 3$ and $C 4$, perpendicular to the two-fold axis relating subunits. 


\section{Table 1}

Crystallographic statistics for the truncated ACS crystal structure.

\begin{tabular}{|c|c|c|c|}
\hline Data & & Refinement & \\
\hline Space group & $\mathrm{P} 3{ }_{1} 21$ & Resolution $(\AA)$ & $20.0-3.0$ \\
\hline Cell dimensions: & & Reflections in work set & 74440 \\
\hline $\mathrm{a}, \mathrm{b}(\AA)$ & 166.4 & $\mathrm{R}_{\mathrm{work}}(\%)$ & 17.1 \\
\hline$c(\AA)$ & 245.2 & Reflections in test set & 3902 \\
\hline Molecules/asymmetric unit & 6 & $\mathrm{R}_{\text {free }}(\%)$ & 20.8 \\
\hline Resolution $(\AA)^{*}$ & $20-3(3.1-3.0)$ & Total number of atoms & 20121 \\
\hline $\mathrm{R}_{\mathrm{sym}}(\%)^{*}$ & $5.3(24.3)$ & Water molecules & 161 \\
\hline$\langle\mathrm{I}\rangle \mid\langle\sigma(\mathrm{I})\rangle^{*}$ & $19.6(6.3)$ & Sulfate molecules & 24 \\
\hline Number of observations $*$ & $588420(55207)$ & Glycerol molecules & 6 \\
\hline Unique reflections $*$ & $78314(7323)$ & $\sigma_{\text {bond }}(\AA)$ & 0.015 \\
\hline \multirow[t]{2}{*}{ Completeness $(\%)^{*}$} & $99.5(99.7)$ & $\sigma_{\text {angle }}\left({ }^{\circ}\right)$ & 1.59 \\
\hline & & average B factor $\left(\AA^{2}\right)$ & 57.3 \\
\hline
\end{tabular}

